\title{
Progressive multifocal leukoencephalopathy unmasked by antiretroviral therapy for HIV
}

\author{
Eric A. Coomes MD, Amila Heendeniya MD, Paul E. Bunce MA MD
}

Cite as: CMAJ 2018 October 22;190:E1260. doi: 10.1503/cmaj.180433

A 51-year-old man with chronic HIV presented to the emergency department with right-hand monoparesis. After years of nonadherence with medication, he had restarted antiretroviral therapy two months before, with successful achievement of viral suppression and an increase in CD4 count from 50 to 84 cells $\times 10^{6} / \mathrm{L}$. Magnetic resonance imaging (MRI) of the patient's brain showed $T_{2}$ hyperintensity in the left precentral gyrus white matter (Figure 1A). His cerebrospinal fluid was normal biochemically. Results from testing for bacteria, fungi, syphilis and mycobacteria, as well as polymerase chain reaction (PCR) for herpesviruses and John Cunningham (JC) polyomavirus, were negative.

Over the next month, the weakness progressed to flaccid paralysis of the right arm and the patient had a seizure. Repeat MRIs showed progression of confluent hyperintense whitematter lesions throughout the left hemisphere, with marked gadolinium enhancement (Figure 1B; a video [Appendix 1] is available at www.cmaj.ca/lookup/suppl/doi:10.1503/cmaj.180433/-/DC1). Given this deterioration, we requested a repeat lumbar puncture. Repeat PCR testing for JC polyomavirus was positive; we diagnosed progressive multifocal leukoencephalopathy with immune reconstitution inflammatory syndrome. The weakness progressed to dense right-sided hemiplegia; we then started treatment with intravenous methylprednisolone followed by oral prednisone, with subsequent tapering over six weeks. The patient's strength and function gradually improved.

John Cunningham polyomavirus, a prevalent latent infection, can reactivate in people who are immunocompromised, causing progressive multifocal leukoencephalopathy, a central demyelinating disease. ${ }^{1}$ Neurologic presentations can be diverse, with typical findings on MRI (Figure 1). Diagnosis is microbiologically confirmed by virus PCR of cerebrospinal fluid or brain tissue. There is no proven specific therapy, and most who recover have substantial neurologic sequelae. ${ }^{2}$ Paradoxically, some patients with HIV receiving antiretroviral therapy may have worsening inflammation after restoration of specific immune responses, known as immune reconstitution inflammatory syndrome. ${ }^{2}$ For this group with severe manifestations, corticosteroid therapy may be considered, despite limited evidence., ${ }^{2,3}$

\section{References}

1. Berger JR, Aksamit AJ, Clifford DB, et al. PML diagnostic criteria: consensus statement from the AAN Neuroinfectious Disease Section. Neurology 2013; 80:1430-8.

2. Tan K, Roda R, Ostrow L, et al. PML-IRIS in patients with HIV infection: clinical manifestations and treatment with steroids. Neurology 2009;72:1458-64.

3. Pavlovic D, Patera AC, Nyberg F, et al.; Progressive Multifocal Leukeoncephalopathy Consortium. Progressive multifocal leukoencephalopathy: current treatment options and future perspectives. Ther Adv Neurol Disord 2015; 8:255-73.

\section{Competing interests: None declared.}

This article has been peer reviewed.

The authors have obtained patient consent.

Affiliations: Department of Medicine (Coomes, Heendeniya, Bunce), University of Toronto; Division of Infectious Diseases (Heendeniya, Bunce), University Health Network, Toronto, Ont.

Correspondence to: Eric Coomes, eric.coomes@mail.utoronto.ca

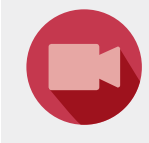

A video of magnetic resonance imaging showing progressive multifocal leukoencephalopathy with immune reconstitution inflammatory syndrome is available in Appendix 1 , at www.cmaj.ca/lookup/suppl/doi:10.1503/cmaj.180433/-/DC1 